\title{
Changes in systolic time intervals in acute myocardial infarction
}

\author{
Roland Samson ${ }^{1}$ \\ From Medical Research Council Cardiovascular Research Unit, Royal Postgraduate \\ Medical School, Hammersmith Hospital, London W.I2
}

\begin{abstract}
After acute myocardial infarction there is a shortening of the $Q S_{2}$ interval and the ejection time. The pre-ejection time is either normal or prolonged. After the stage of maximum shortening of the $Q S_{2}$ interval and ejection time, there is a progressize improvement towards the normal. In this study there was no correlation between the shortened $Q S_{2}$ interval and ejection time, and the level of urinary catecholamine excretion.

The physiological and clinical significance of these changes in the systolic time intervals and their relation to the altered haemodynamics and mechanics are discussed.
\end{abstract}

The evaluation of the systolic time intervals as a bloodless method of measuring cardiovascular function is of interest to cardiologists and clinicans. Garrod (1874), Lombard and Cope (1926), and Braunwald, Sarnoff, and Stainsby (1958) noted an inverse relation between the left ventricular ejection time (ejection time) and heart rate. Ježek (I963) described some of the changes in systolic time intervals in both myocardial and valvular heart disease. Weissler, Harris, and Schoenfeld (1968) found a normal Q-second heart sound interval ( $\left(\mathrm{QS}_{2}\right.$ interval) with a shortened ejection time and prolonged pre-ejection time in patients with chronic myocardial disease, who were in heart failure. We have previously described (Toutouzas et al., I969) some of the patterns of change of the $\mathrm{QS}_{2}$ interval after acute myocardial infarction.

This paper describes the magnitude and course of the changes occurring in the systolic time intervals in patients after acute myocardial infarction. In view of the fact that the ejection time is known to be influenced by inotropic agents (Braunwald et al., 1958; Wallace, 1968), and as urinary catecholamines are increased in patients following acute myocardial infarction (Gazes, Richardson, and Woods, 1959; Nuzum and Bischoff, 1953; Valori, Thomas, and Shillingford, 1967; Wallace, 1968), we have also attempted to determine whether there is any correlation

Received I8 March I970.

${ }^{1}$ In receipt of a grant from the British Heart Foundation. between the systolic time interval and catecholamine excretion.

\section{Methods}

Thirty-one patients with acute myocardial infarction were studied. The patients were accepted for study if they showed the typical signs of acute myocardial infarction with chest pain, diagnostic changes in the electrocardiogram, and an increase in the serum lactic dehydrogenase. Patients with electrocardiographic evidence of bundle-branch block, raised systemic arterial pressure, and those receiving digitalis were excluded from the study.

The patients were grouped clinically according to the absence (Group I) or presence (Group 2) of radiological pulmonary oedema and major arrhythmias. There were 15 patients in Group I and 16 patients in Group 2.

The electrocardiogram, phonocardiogram, and the external carotid arterial pulse tracing were recorded simultaneously on an Elema Schonander Minograph recorder at a paper speed of 100 $\mathrm{mm}$./sec. The recording was done during held quiet respiration in the supine position. The patients were studied at a fixed time daily or on alternate days, from the day of admission to the day of discharge and thereafter at a time which varied between 2 and 8 months.

The $\mathrm{QS}_{2}$ interval was measured from the onset of the $Q$ wave to the onset of the aortic component of the second heart sound, which was taken as the beginning of the first high frequency vibration. The left ventricular ejection time (ejection time) was measured from the upstroke of the incisura of the carotid pulse tracing to its trough. The preejection period was obtained by subtracting the ejection time from the $\mathrm{QS}_{2}$ interval. Five consecutive cycles were measured and averaged for the final reading. Measurements were only made 
if the initial vibration of the first and second heart sounds and the beginning of the upstroke and the trough of the incisura were clearly shown on the recordings.

The regression equation relating heart rate to the systolic time intervals in normal subjects has already been established with a standard deviation of $14 \mathrm{msec}$. for the $\mathrm{QS}_{2}$ interval, Io $\mathrm{msec}$. for the ejection time, and $13 \mathrm{msec}$. for the pre-ejection time (Weissler et al., 1968). The magnitude of change in the systolic time intervals was obtained by subtracting the observed value from the mean normal value at the same heart rate, and expressed in the results as the decrease or shortening in the $\mathbf{Q S}_{2}$ interval and ejection time and as an increase in the pre-ejection time in milliseconds (msec.).

Urine was collected from II patients daily, during the first 5 days of admission, for catecholamine estimation in an attempt to correlate changes in the systolic time intervals with sympathetic activity.

\section{Results}

In each patient the $Q S_{2}$ interval and the ejection time were abnormally shortened at some stage during the illness, usually during the acute phase. The changes in the systolic time intervals occurring in the $3 \mathrm{I}$ patients during the course of acute myocardial infarction can be illustrated by comparing the mean shortening of the $Q S_{2}$ interval and ejection time at the time of maximum shortening, at discharge, and at the follow-up. The changes are shown in Fig. I. This shows a progressive improvement in the mean values of the $\mathrm{QS}_{2}$ interval and ejection time shortening.

The magnitude of shortening of the $\mathrm{QS}_{2}$ interval and ejection time was related to the clinical state, as shown in Fig. 2. The patients

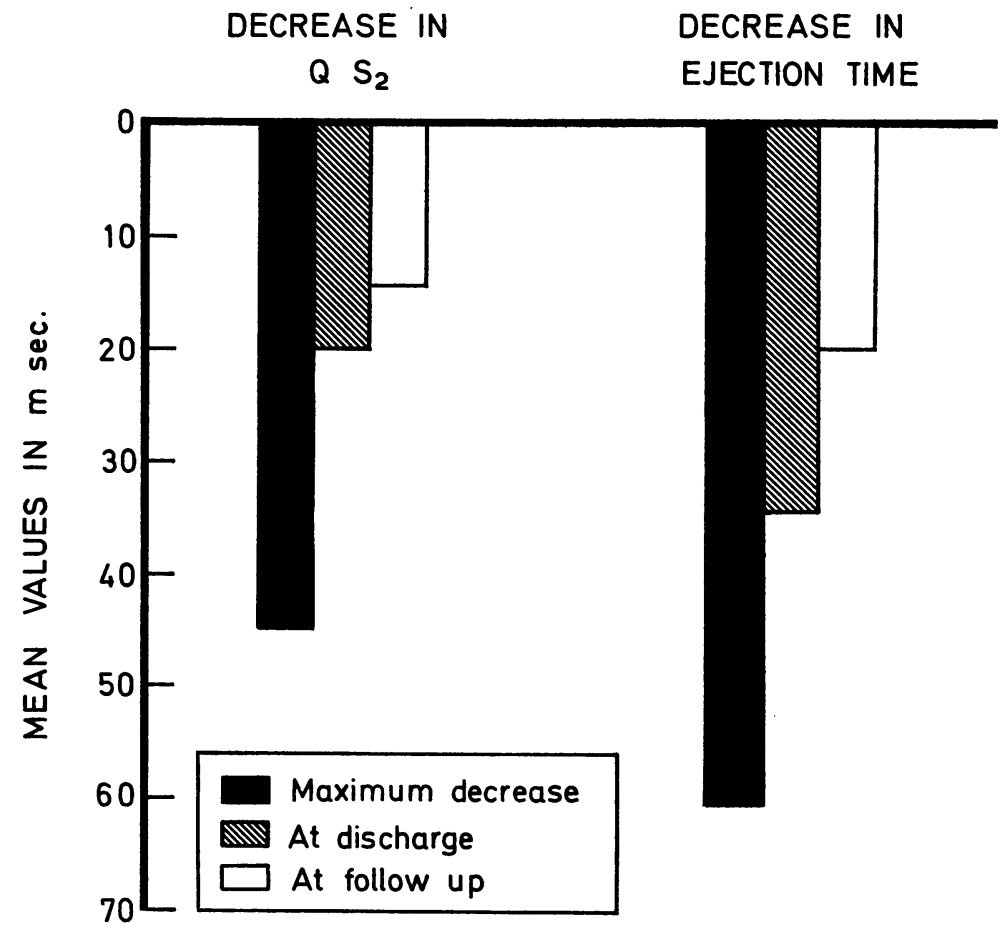

FIG. I The mean decrease in the $Q S_{2}$ interval and the ejection time in 31 patients at the stage of maximum decrease, at discharge from hospital, and at the time of the follow-up measurement.

TABLE I Shows a distinction between clinical Groups I and 2, both in mean and in maximum decrease in $Q S_{2}$ interval and in mean and maximum decrease in ejection time

(a) $Q S_{2}$ interval

\begin{tabular}{|c|c|c|c|c|}
\hline & \multicolumn{2}{|c|}{$\begin{array}{l}\text { Separation of mean decrease in } \\
Q S_{2} \text { interval into those with values }\end{array}$} & \multicolumn{2}{|c|}{$\begin{array}{l}\text { Separation of maximum decrease in } \\
Q S_{2} \text { interval into those with values }\end{array}$} \\
\hline & Under $30 \mathrm{msec}$. & $31 \mathrm{msec}$. and over & Under $50 \mathrm{msec}$. & $5 I$ msec. and over \\
\hline $\begin{array}{l}\text { Group I (15 patients) } \\
\text { Group } 2 \text { (I6 patients) }\end{array}$ & $\begin{array}{l}13 \text { patients } \\
3 \text { patients }\end{array}$ & $\begin{array}{l}2 \text { patients } \\
13 \text { patients }\end{array}$ & $\begin{array}{l}\text { I2 patients } \\
3 \text { patients }\end{array}$ & $\begin{array}{l}3 \text { patients } \\
\text { 13 patients }\end{array}$ \\
\hline
\end{tabular}

(b) Ejection time

\begin{tabular}{|c|c|c|c|c|}
\hline & \multicolumn{2}{|c|}{$\begin{array}{l}\text { Separation of mean decrease in } \\
E T \text { into those with values }\end{array}$} & \multicolumn{2}{|c|}{$\begin{array}{l}\text { Separation of maximum decrease } \\
\text { in ET into those with values }\end{array}$} \\
\hline & Under 40 msec. & 41 msec. and over & Under 61 msec. & $6 I$ msec. and over \\
\hline $\begin{array}{l}\text { Group I (I5 patients) } \\
\text { Group } 2 \text { (I6 patients) }\end{array}$ & $\begin{array}{l}\text { I I patients } \\
3 \text { patients }\end{array}$ & $\begin{array}{l}4 \text { patients } \\
\text { I3 patients }\end{array}$ & $\begin{array}{l}12 \text { patients } \\
2 \text { patients }\end{array}$ & $\begin{array}{l}3 \text { patients } \\
\text { I4 patients }\end{array}$ \\
\hline
\end{tabular}


in Group I had a mean $Q S_{2}$ shortening of 18 msec. (a range of shortening of 5 to $35 \mathrm{msec}$.) and a mean ejection time shortening of 33 msec. (a range of shortening of 12 to $45 \mathrm{msec}$.). The patients in Group 2 had a mean $\mathrm{QS}_{2}$ shortening of $40 \mathrm{msec}$. (a range of shortening of 16 to $64 \mathrm{msec}$.) and a mean ejection time shortening of $52 \mathrm{msec}$. (a range of shortening of 32 to $74 \mathrm{msec}$.). The $\mathrm{QS}_{2}$ and ejection time intervals were more significantly decreased in Group 2 than in Group I patients.

The degree of change in the shortened $\mathrm{QS}_{2}$ interval and ejection time occurring in the patients in Group I and in patients in Group 2 during the course of their illness is shown in Fig. 3. At each stage, the patients in Group 2 had more significantly shortened $\mathrm{QS}_{2}$ and ejection time intervals.

The change in the pre-ejection period in the two groups is shown in Fig. 4. The mean pre-ejection was slightly more prolonged in Group 2 patients than those in Group I.

The ratio of pre-ejection time to the ejection time ( $\mathrm{P} / \mathrm{E}$ ratio) was not significantly different in the two groups. Group I had a mean P/E ratio of 0.456 (range 0.307 to 0.569 ) and Group 2 had a mean P/E ratio of 0.464 (range 0.310 to 0.579 ). The normal values are a mean of 0.345 , with a range of 0.309 to $0.38 \mathrm{I}$ (Weissler, Harris, and Schoenfeld, I969).

In order to show a further distinction between the two clinical groups, the mean values and the values at maximum decrease of the $\mathrm{QS}_{2}$ interval and ejection time shortening were arbitrarily divided into two groups. This was done by choosing a value at which there was an obvious separation of the data into two groups. The distinction was sufficiently clear to warrant documenting the values. The value around which separation was made is indicated in Table I with the number of patients from Group I and Group 2 who fell under such separation. This shows that the mean value and the maximum value of shortening of the $\mathrm{QS}_{2}$ interval and ejection time was greater in Group 2 than in Group I patients.

A comparison between the changes in the $\mathrm{QS}_{2}$ interval and ejection time and the level of urinary catecholamine excretion is shown in Fig. 5 to 8. Fig. 5 and 6 show the daily values for $\mathrm{QS}_{2}$ and ejection time shortening and the mean daily value of adrenaline and noradrenaline excretion in one patient over six days. This shows no correlation between the catecholamine value and the $\mathrm{QS}_{2}$ and ejection time values. Fig. 7 and Fig. 8 show the mean values of $\mathrm{QS}_{2}$ and ejection time shortening and the mean values of the daily

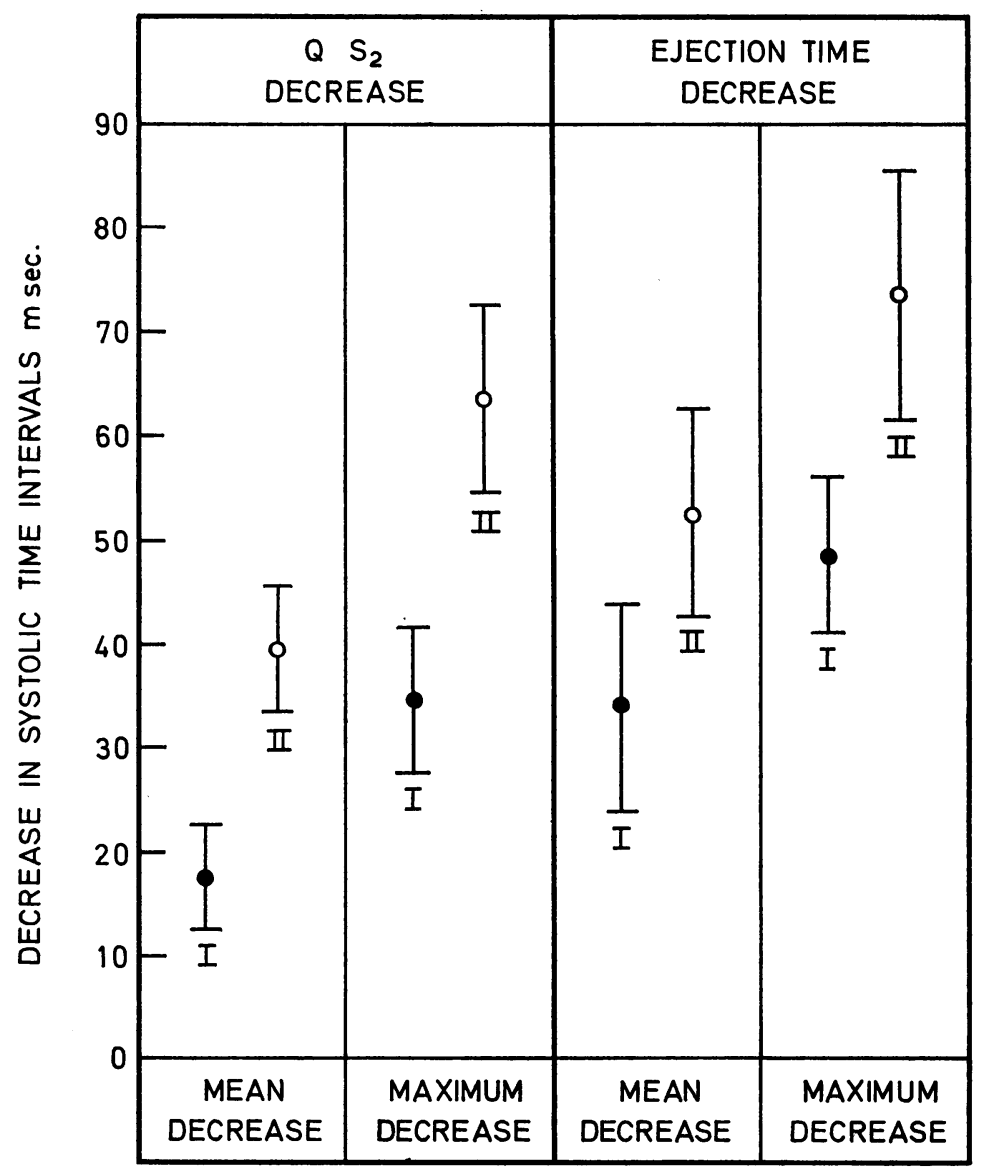

FIG. 2 Comparison between clinical Group I and clinical Group 2 in the mean and the maximum decrease in the $Q S_{2}$ interval and the ejection time. The limits show the standard error of the mean.

adrenaline and noradrenaline excretion over 5 days in II patients. This shows no correlation between the mean daily catecholamine excretion and the mean $\mathrm{QS}_{2}$ and ejection time shortening. Table 2 shows a comparison between the $\mathrm{QS}_{2}$ decrease and the urine catecholamine excretion in the II patients who have been divided into those with radiological pulmonary oedema and major arrhythmias (Group 2) and those without radiological pulmonary oedema and major arrhythmias (Group I). There were 5 patients in Group 2 and 6 patients in Group I. This shows that patients in Group 2 had a greater $\mathrm{QS}_{2}$ decrease and a greater catecholamine excretion.

\section{Discussion}

Our results show a shortening of the $\mathrm{QS}_{2}$ interval and ejection time after acute myocardial infarction and a gradual return towards 


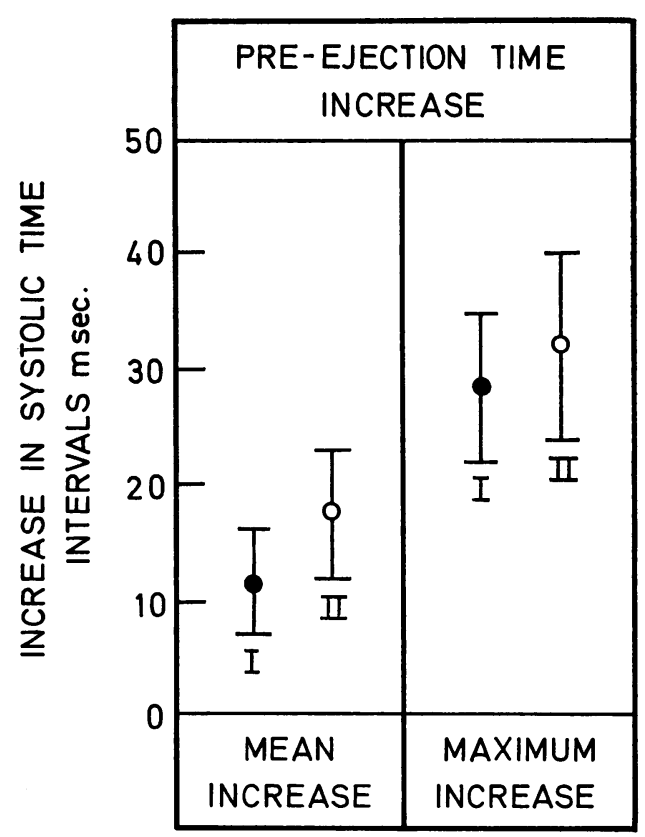

FIG. 4 Comparison between clinical Group I and clinical Group 2 in the mean and the maximum increase in the pre-ejection period.

normal in the majority of patients. This is in agreement with the work of Wiggers in experimental animals (Wiggers, 1945) and the work of Ježek (1963) in man, which showed a shortened ejection time after acute myocardial infarction, and our previous studies (Toutouzas et al., 1969) which showed a shortened $\mathrm{QS}_{2}$ interval in this disease. The pre-ejection period is either normal or prolonged. In addition, our results show the ejection time to be shorter than the $\mathrm{QS}_{2}$ interval. After admission the $\mathrm{QS}_{2}$ interval and ejection time tended to become shorter after a variable period, reaching a maximum shortening during the first week. Before discharge, the majority were returning towards the normal, and this trend continued at the time of followup.

We have shown that the degree of shortening of the $\mathrm{QS}_{2}$ interval and the ejection time correlated with the severity of the clinical state as judged by pulmonary oedema and major arrhythmias. The daily $\mathrm{QS}_{2}$ interval and ejection time shortening did not correlate with the mean daily catecholamine excretion. However, the patients who were more ill with pulmonary oedema and major arrhythmias had a greater degree of shortening of the $\mathrm{QS}_{2}$ interval and ejection time and a greater increase in catecholamine excretion.

The mechanism of the changes in the sys-

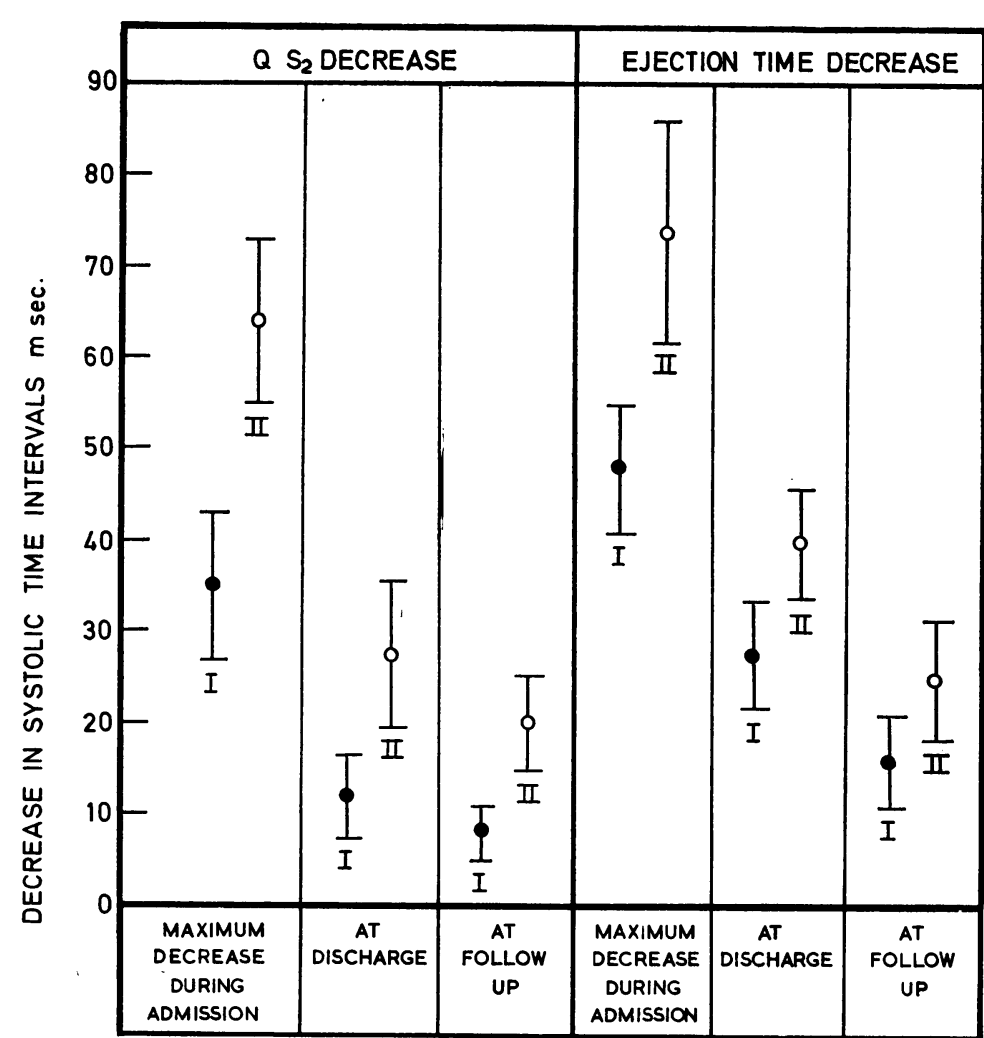

FIG. 3 Comparison between Group I and Group 2 patients in the mean values at the time of maximum shortening, at discharge, and at the follow-up measurement.

tolic time intervals in patients with acute myocardial infarction is of physiological and clinical interest.

As our patients had no prolongation of ventricular depolarization time, the prolonged pre-ejection period could be due to an increase in the isovolumetric time. We are not aware of any data of intraventricular measurements

TABLE 2 Comparison between mean decrease in $Q S_{2}$ interval and mean adrenaline and noradrenaline excretion in Group $I$ and Group 2 patients over 5 days after an acute myocardial infarction

\begin{tabular}{|c|c|c|c|}
\hline \multirow{2}{*}{$\begin{array}{l}\text { Clinical group } \\
\text { (II patients) }\end{array}$} & \multirow{2}{*}{$\begin{array}{l}\text { Mean decrease in } \\
Q S_{2} \text { interval }\end{array}$} & \multicolumn{2}{|c|}{ Mean urinary catecholamine excretion } \\
\hline & & Adrenaline & Noradrenaline \\
\hline Group I (6 patients) & 18 (msec.) & $\begin{array}{l}4.71(1.32-6.8) \\
\mu g . / g \text {. creatine }\end{array}$ & $37 \cdot 6(24 \cdot 2-6 I \cdot 5)$ \\
\hline Group 2 ( 5 patients) & 40 (msec.) & $20 \cdot 17(5 \cdot 7-52)$ & $94.5(65-137)$ \\
\hline
\end{tabular}




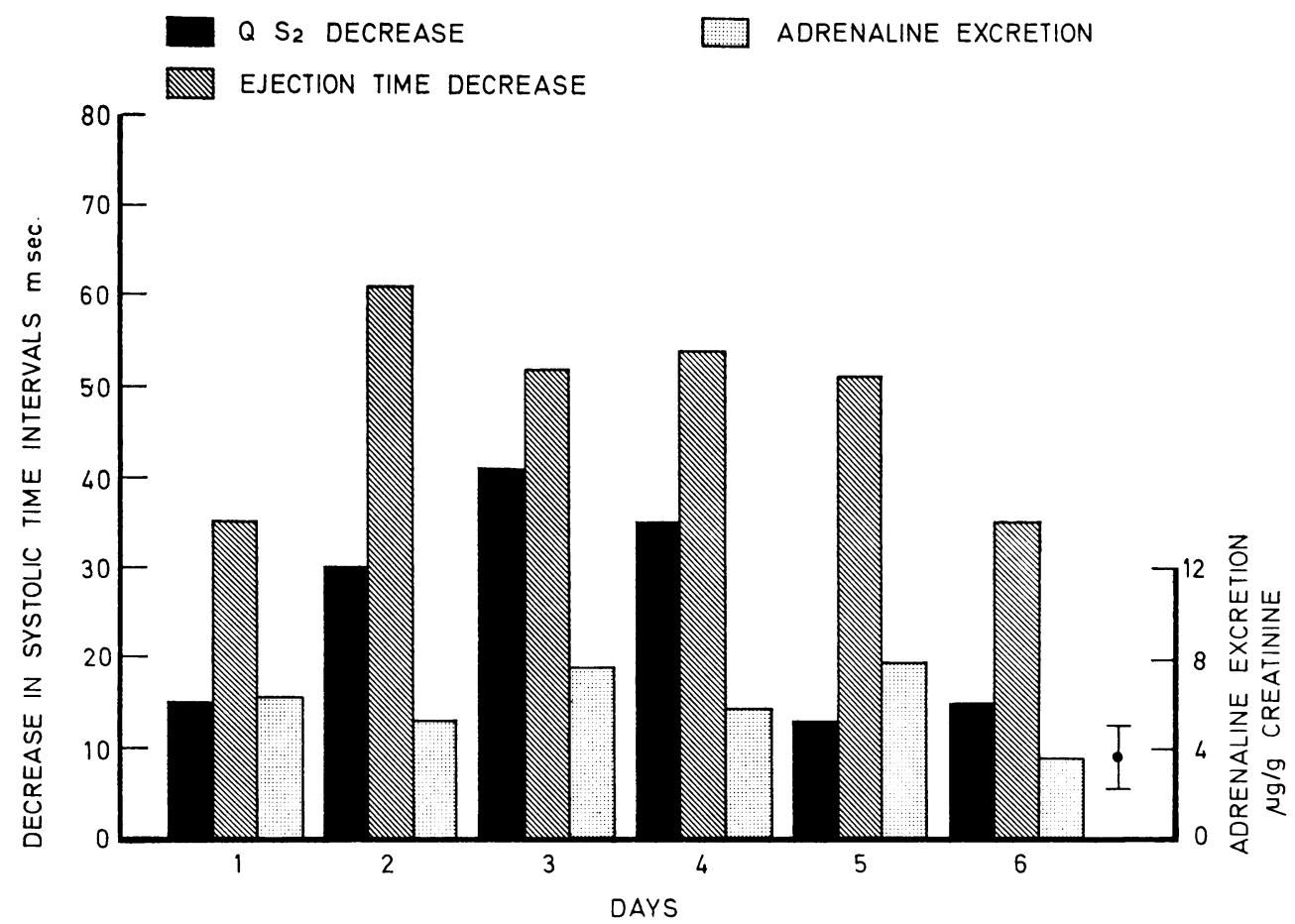

FIG. 5 Comparison between the urinary level of adrenaline excretion and the decrease in the $Q S_{2}$ interval and ejection time in one patient observed daily over 6 days.

FIG. 6 Comparison between the urinary level of noradrenaline excretion and the decrease in the $Q S_{2}$ interval and ejection time in one patient observed daily over 6 days.

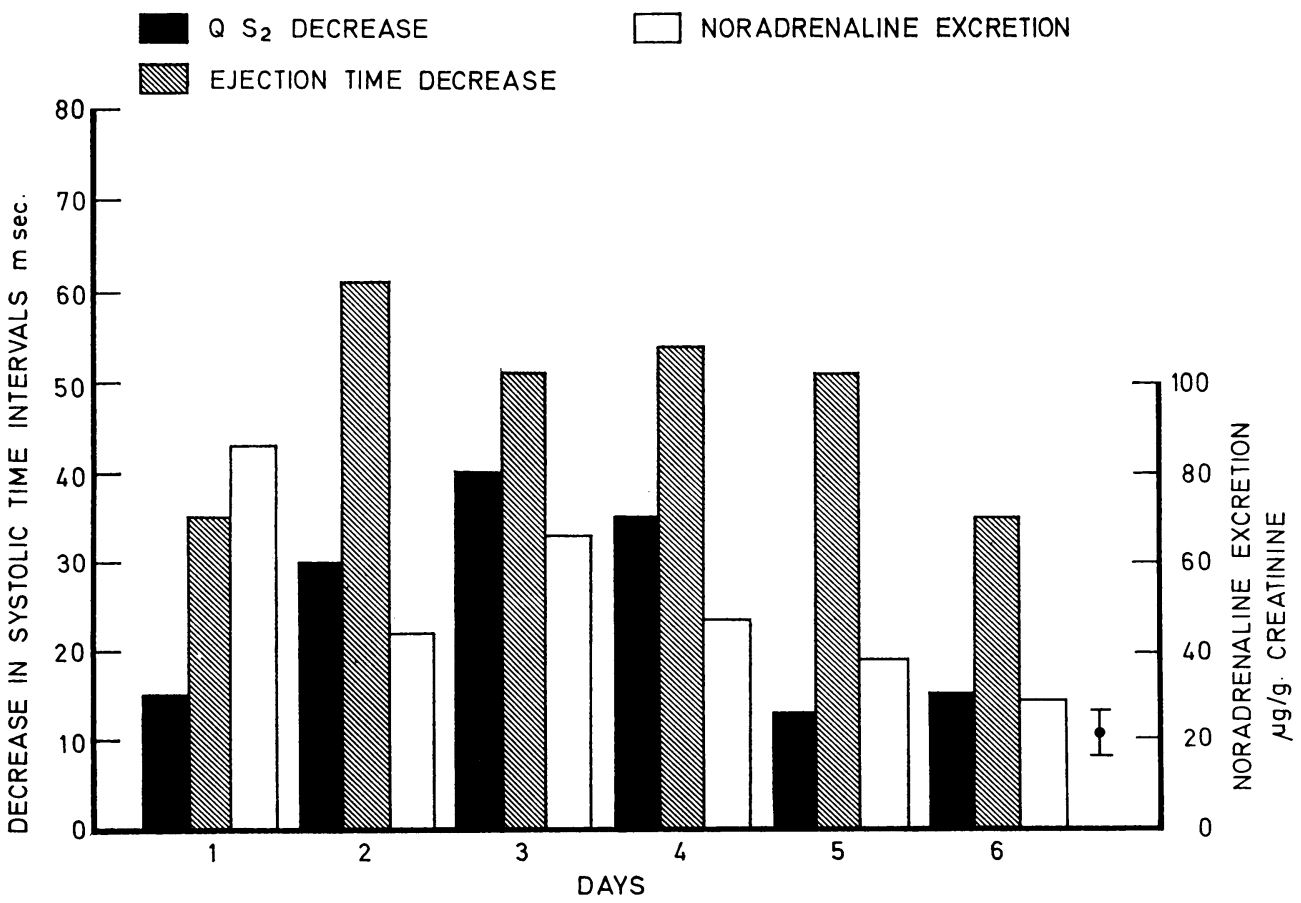




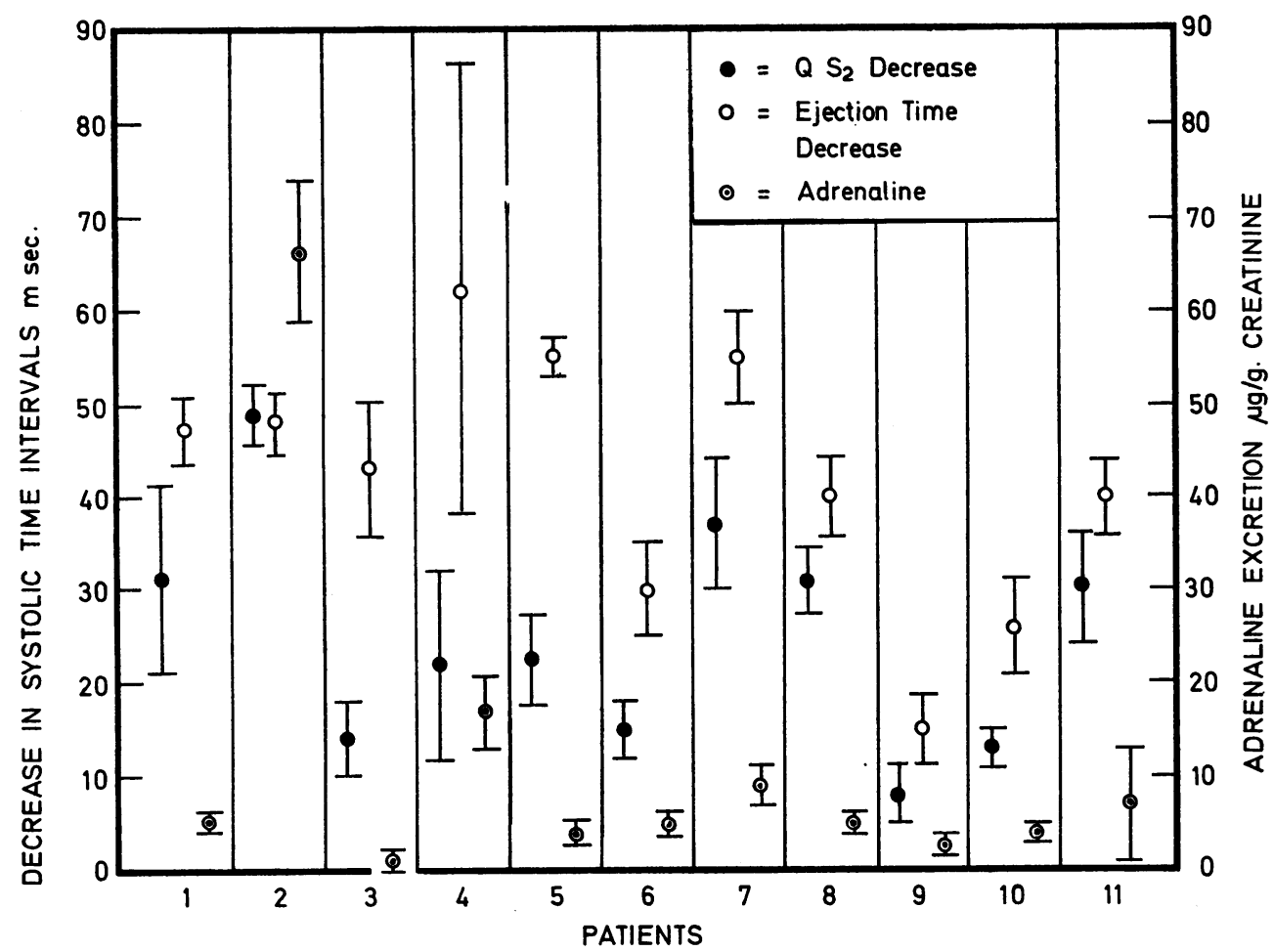

FIG. 7 Comparison between the mean values of urinary adrenaline excretion and the mean decrease in $Q S_{2}$ interval and ejection time in I I patients each studied over the first 5 days of admission after an acute myocardial infarction.

of the isovolumetric period in patients with acute myocardial infarction. Atraumatic clinical methods of determining the isovolumetric period are as yet too inaccurate. In experimental myocardial infarction, Wiggers (1945) observed a slow rise of pressure during the isovolumetric period and ballooning of the infarcted area during the isovolumetric and ejection periods.

The shortening of the $\mathrm{QS}_{2}$ interval is predominantly due to shortening of the ejection time. Factors known to shorten the ejection time are physiological variables, such as an increased heart rate, decreased myocardial contractility, and decreased stroke volume (Weissler, Peeler, and Roehll, 196I), and inotropic agents such as catecholamines, hypercalcaemia (Seifen, Flacke, and Alper, 1964; Shiner, Harris, and Weissler, 1969), digitalis (Weissler et al., 1965), and isoprenaline.

Further study is required for a clear understanding of the mechanisms and significance of the shortened ejection time occurring after acute myocardial infarction. However, certain considerations concerning the measured ejection time and the cardiac function after acute myocardial infarction are relevant. Weissler et al. (1965) showed that the ejection time as measured at the external carotid artery is related to the central aortic ejection time. They also showed a direct relation between ejection time and stroke volume in normal man and in patients with myocardial failure with chronic myocardial disease. Some of the features of cardiac function after acute infarction include an altered myocardial contractility, reduced stroke volume, and a reduced stroke velocity.

The infarcted site behaves as an area of increased compliance, and presents clinically, in many cases, as an area of paradoxical systolic pulsation over the praecordium, resulting in asynergic contraction and reduction in the over-all contractile force. In this respect the area of infarction may behave as the focal areas of altered contraction in patients with coronary heart disease, as described by Herman and Gorlin (1969), who suggest that the 'slack' area of paradoxical systolic pulsation may account for the slower rise of pressure during the isovolumetric period with reduction in the rate of over-all tension development. More contractile element is therefore utilized in the development of ten- 


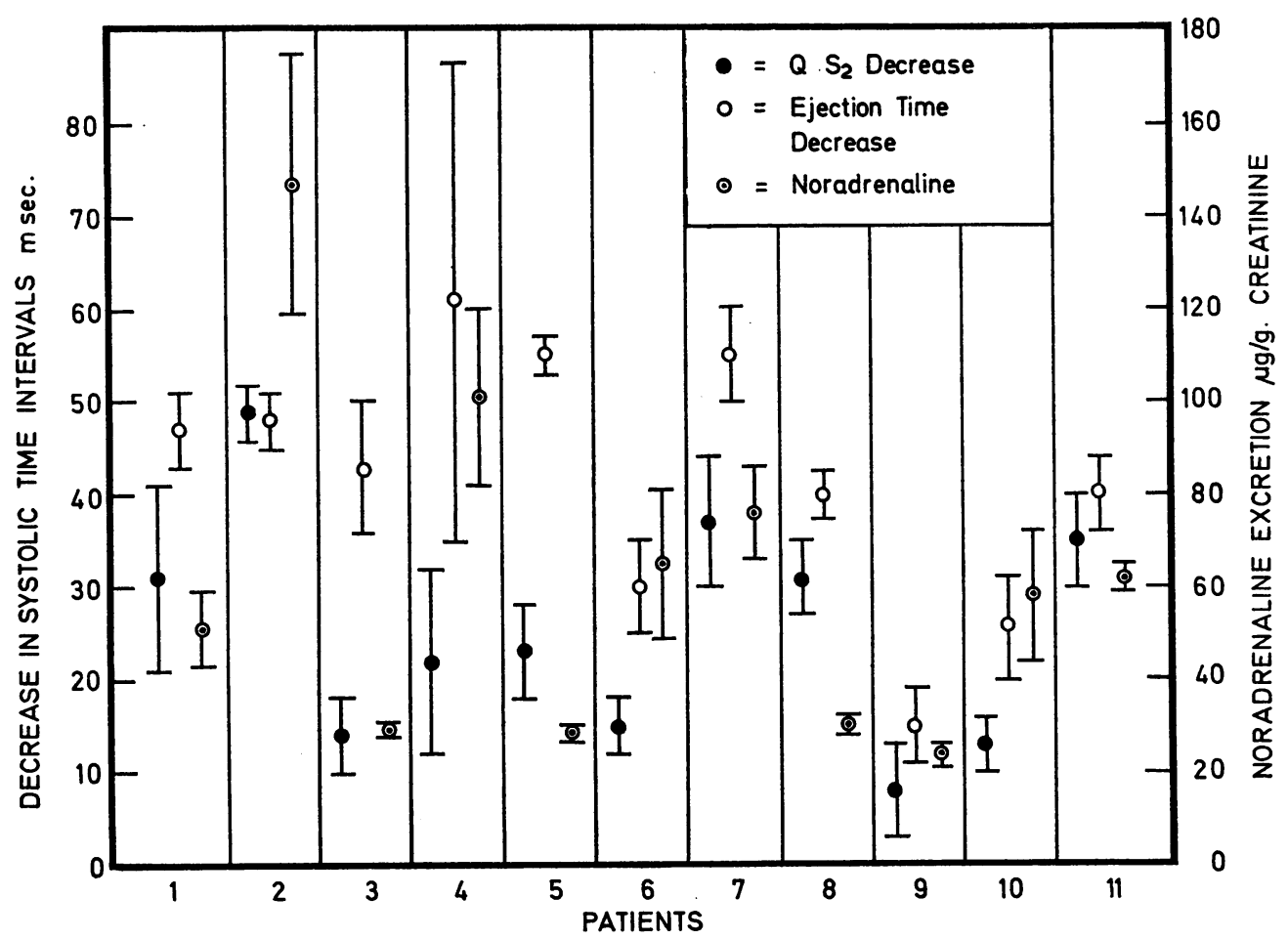

FIG. 8 Comparison between the mean values of urinary noradrenaline excretion and the mean decrease in $Q S_{2}$ interval and ejection and ejection time in II patients each studied over the first 5 days of admission after an acute myocardial infarction.

sion and less remains available for expulsion of blood.

As there are dynamic cellular changes at the infarcted area with thinning and later scarring of the muscle wall (Lodge-Patch, 195I), there may well be related changes in compliance at this site and changes in contraction and in the over-all contractile force. The measurement of compliance and contraction would be important for a clearer appreciation of their significance, and of their relation to atraumatic clinical measurements such as the ejection time.

Haemodynamic studies in man after acute myocardial infarction appear to be in agreement on the finding of a reduced stroke volume which improves during recovery and which is related to the clinical state (Smith, Wikler, and Fox, 1954; Gilbert, Goldberg, and Griffin, 1954; Gammill et al., 1955; Broch et al., 1959; Murphy et al., 1963). Doing serial studies, Nager, Thomas, and Shillingford (1967) found that the reduced stroke volume reached a maximum around the 3rd and 4th day, followed by progressive improvement, the magnitude of which depended on the clinical severity of the case.
The stroke velocity is also reduced, as shown by Mills using a catheter tip velocity probe (C. Mills, 1969, personal communication).

The infarcted myocardium, with its reduced contractile force, seems to eject a smaller volume, at a reduced velocity and in a shorter time. Thus the shortened ejection time may be used as an index of cardiac function in patients after acute myocardial infarction. It could provide us with information regarding the stroke volume, and in this respect it could be more sensitive than the $\mathrm{QS}_{2}$ interval.

The presence of pulmonary oedema and major arrhythmias in patients with an acute myocardial infarction could well argue a smaller stroke volume in comparison with those without these associated complications. This could be in keeping with the shorter ejection time observed in the Group 2 patients.

The patients in Group 2 with a shorter ejection time had a higher level of urinary catecholamine excretion. We have no evidence as yet that the catecholamine level in this situation plays any dominant role in shortening the ejection time. The mechanism of increased serum catecholamine in acute myocardial infarction is still unknown. 
In this regard, we must conclude that the shortened ejection time and the raised catecholamine levels have no direct relation but are associated features of acute myocardial infarction and both undergo progressive change during the course of the illness.

I wish to thank Professor J. P. Shillingford for his encouragement, Dr. Michael Thomas, Dr. Ivor Gabe, and Mr. Christopher Mills for their helpful suggestions, and Mr. Peter Burgess and Miss Jean Powell for their invaluable technical assistance.

\section{References}

Braunwald, E., Sarnoff, S. J., and Stainsby, W. N. (1958). Determinants of duration and mean rate of ventricular ejection. Circulation Research, 6, 319.

Broch, O. J., Humerfelt, S., Haarstad, J., and Myhre, J. R. (1959). Hemodynamic studies in acute myocardial infarction. American Heart fournal, 57, 522.

Gammill, J. F., Applegarth, J. J., Reed, C. E., Fernald, J. D., and Antenucci, A. J. (1955). Hemodynamic changes following acute myocardial infarction using the dye injection method for cardiac output determination. Annals of Internal Medicine, 43, Ioo.

Garrod, A. H. (1874). On some points connected with the circulation of the blood, arrived at from a study of the sphygmograph-trace. Proceedings of Royal Society of London, 23, 140.

Gazes, P. C., Richardson, J. A., and Woods, E. F. (1959). Plasma catecholamine concentrations in myocardial infarction and angina pectoris. Circulation, 19, 657.

Gilbert, R. P., Goldberg, M., and Griffin, J. (1954). Circulatory changes in acute myocardial infarction. Circulation, 9, 847.

Herman, M. V., and Gorlin, R. (1969). Implications of left ventricular asynergy. American fournal of Cardiology, 23, 538 .

Ježek, V. (1963). Clinical value of the polygraphic tracing in the study of the sequence of events during cardiac contraction. Cardiologia, 43, 298.

Lodge-Patch, I. (195I). The ageing of cardiac infarcts, and its influence on cardiac rupture. British Heart fournal, 13, 37.

Lombard, W. P., and Cope, O. M. (1926). The duration of the systole of the left ventricle of man. American fournal of Physiology, 77, 263.
Murphy, G. W., Glick, G., Schreiner, B. F., and Yu, P. N. (1963). Cardiac output in acute myocardial infarction. Serial determination by precordial radioisotope dilution curves. American fournal of Cardiology, I1, 587.

Nager, F., Thomas, M., and Shillingford, J. (1967). Changes in cardiac output and stroke volume during first four months after cardiac infarction. British Heart fournal, 29, 859.

Nuzum, F. R., and Bischoff, F. (1953). The urinary output of catechol derivatives including adrenaline in normal individuals, in essential hypertension, and in myocardial infarction. Circulation, 7, 96.

Seifen, E., Flacke, W., and Alper, M. H. (1964). Effects of calcium on isolated mammalian heart. American fournal of Physiology, 207, 716.

Shiner, P. T., Harris, W. S., and Weissler, A. M. (1969). Effects of acute changes in serum calcium levels on the systolic time intervals in man. American fournal of Cardiology, 24, 42.

Smith, W. W., Wikler, N. S., and Fox, A. C. (1954). Hemodynamic studies of patients with myocardial infarction. Circulation, 9, 352.

Toutouzas, P., Gupta, D., Samson, R., and Shillingford, J. (1969). Q-second sound interval in acute myocardial infarction. British Heart fournal, 31, 462.

Valori, C., Thomas, M., and Shillingford, J. (1967). Free noradrenaline and adrenaline excretion in relation to clinical syndromes following myocardial infarction. American fournal of Cardiology, 20, 605.

Wallace, A. G. (1968). Catecholamine metabolism in patients with acute myocardial infarction. In Acute Myocardial Infarction: Proceedings of a Symposium, Edinburgh, 1967, p. 237. Ed. by D. G. Julian and M. F. Oliver. E. \& S. Livingstone, Edinburgh.

Weissler, A. M., Harris, W. S., and Schoenfeld, C. D. (1968). Systolic time intervals in heart failure in man. Circulation, 37, 149.

$\longrightarrow,-$ and - (1969). Bedside technics for the evaluation of ventricular function in man. American fournal of Cardiology, 23, 577.

- Kamen, A. R., Bornstein, R. S., Schoenfeld, C. D., and Cohen, S. (1965). The effect of deslanoside on the duration of the phases of ventricular systole in man. American fournal of Cardiology, 15, I53.

, Peeler, R. G., and Roehll, W. H. (196I). Relationships between left ventricular ejection time, stroke volume, and heart rate in normal individuals and patients with cardiovascular disease. American Heart fournal, 62, 367.

Wiggers, C. J. (1945). The functional consequences of coronary occlusion. Annals of Internal Medicine, 23, 158 . 